\title{
Ética em publicações científicas: um trabalho de todo dia - a busca do valor absoluto no mundo relativizado
}

\author{
Ethics in scientific publication: an everyday work - \\ the search for an absolute value in a relativized world
}

\author{
Eduardo M.Rocha
}

Ética se refere a reflexões sobre o certo e errado frente aos valores de um grupo social. Ela faz intersecção com a moral, com o conjunto das leis e com os usos e costumes, mas não é sinônimo ou substituto de nenhum deles. O centro do seu conceito deve ser o bem-estar desse grupo ou comunidade.

A ciência médica ultrapassa barreiras impensáveis e os Arquivos Brasileiros de Oftalmologia (ABO), como veículo dessas informações, está chegando a uma comunidade cada vez maior e mais distante. Isso se deu pelas indexações nas ferramentas de busca (PubMed e ISI) assim como pelo acesso eletrônico gratuito via Scielo ${ }^{(1)}$.

Em anos recentes o tema da ética na pesquisa e na publicação cientifica foi abordado em editoriais dos $\mathrm{ABO}$, de forma competente e didática ${ }^{(2-4)}$. O papel e a responsabilidade do elenco de autores foi também tema de editorial ${ }^{(5)}$. Todo jovem ou veterano autor pode e deve se orientar sobre a importância do termo de consentimento para todos os envolvidos: sujeitos e autores de pesquisa ${ }^{(4)}$.

Em editorial de 2008, a justificativa e caminho para obtenção de aprovação prévia por comitê de ética foi claramente exposta. O texto esclarece que todos os tipos de artigos, provenientes de instituições públicas ou privadas, devem e podem recorrer aos comitês de ética em pesquisa ${ }^{(3)}$. A Comissão Nacional de Ética em Pesquisa (CONEP) está pronta para orientar e oferecer esse serviço de utilidade pública ${ }^{(6)}$. Da mesma forma, o artigo revela que os $\mathrm{ABO}$ é signatário de acordo que prevê a exigência de comprovação de aprovação ética de todo estudo a ser publicado em suas páginas ${ }^{(7)}$.

Observada a crescente universalização dos $\mathrm{ABO}$, tanto na busca de informações como na divulgação de trabalhos de diferentes partes do mundo, questionamentos internacionais surgirão, e os padrões de aprovação e condução do estudo, adotados pelos autores, deverão ser avaliados em cada caso. O Brasil tem um excelente padrão referencial de controle das pesquisas em seres humanos, oferecido pelo Sistema Nacional de Informações sobre Ética em Pesquisa Envolvendo Seres Humanos (SISNEP) ${ }^{(8)}$. Os estudos também são avaliados internamente, nas instituições, sendo previsível que variações institucionais ocorram em função das diferenças na cultura interna e em correntes de pensamento.
Ao aprovar um estudo e emitir um documento prévio a sua execução, o comitê de ética em pesquisa (CEP), pode não ser capaz de antever problemas abordados durante o andamento do estudo e não ter condições de monitorar o seu fiel cumprimento. Para isso, comitês de acompanhamento ou auditoria de estudos foram sugeridos ${ }^{(9)}$.

Autores de pesquisas realizadas em regiões do mundo que não possuem CEP ou que sofram com a forma de atuação desses comitês, devem ser avaliados para publicação desde que sejam salvaguardados os conceitos da análise prévia por indivíduos independentes, o termo de consentimento livre e esclarecido (TCLE) e as normas internacionais que protegem os direitos de pacientes ou animais. Devemos contribuir para que, desta maneira, seja promovida a educação para ética evitando que estes locais tornem-se bolsões de clandestinidade em experimentação médica. Da mesma forma, autores e leitores que observem entraves alheios a princípios éticos, mas vinculados a divergências por conflitos de interesse ou políticos, devem ter espaço para expressar isso. Retardar ou dificultar a aprovação de projetos, condução de pesquisas ou avaliação de manuscritos, interfere na qualidade científica e informativa da comunidade.

Apesar de muito bem vindas, pesquisas experimentais ainda são pouco frequentes nos ABO. Informações muito importantes para a ciência médica vieram de estudos com animais e a comunidade científica deve estar atenta às condições a que os animais estão expostos ${ }^{(10-11)}$. Essas também devem ser objeto de análise prévia por comitê de ética em pesquisa animal, como vem ocorrendo em todo mundo nas últimas décadas e tornouse obrigação legal no Brasil, a partir da regulamentação da "Lei Arouca" em 2009 $9^{(12-13)}$.

A editoria dos ABO ressalta o excelente esforço e os resultados obtidos na ética de publicações, fruto do trabalho de autores, leitores e editores anteriores, e enfatiza que aspectos fundamentais e conceituais serão considerados acima e além das formalidades e conjunturas. Em última análise a editoria deverá zelar pela ética nas publicações, salvaguardando pacientes, leitores e autores; ou seja, os valores da sua comunidade. 


\section{REFERÊNCIAS}

1. Muccioli C. O comitê de ética em pesquisa (CEP) e as publicações científicas [editorial]. Arq Bras Oftalmol [Internet]. 2004 [citado 2010 Jun 20];67(2):195-6. Disponível em: http://www.scielo.br/pdf/abo/v67n2/19739.pdf

2. Muccioli C, Dantas P, Campos M, Bicas HE. Relevância do comitê de ética em pesquisa nas publicações científicas [editorial]. Arq Bras Oftalmol [Internet] 2008 [citado 2010 Jun 20];71(6):773-4. Disponível em: http://www.scielo.br/ pdf/abo/v71n6/a01v71n6.pdf

3. Silva L, Oliveira F, Muccioli C. O processo de consentimento na pesquisa clínica: da elaboração a obtenção. Arq Bras Oftalmol [Internet]. 2005 [citado 2010 Jun 20];68(5):704-7. Disponível em: http://www.scielo.br/pdf/abo/v68n5/26751.pdf

4. Muccioli C, Campos M, Goldchmit M, Dantas P, Bechara S, Costa V. A ética, a pesquisa e a publicação científica [editorial]. Arq Bras Oftalmol [Internet]. 2006 [citado 2010 Jun 20];69(6):787. Disponível em: http://www.scielo.br/pdf/ abo/v69n6/a01v69n6.pdf

5. Brasil. Ministério da Saúde. Conselho Nacional de Saúde. Comissão Nacional de Ética em Pesquisa. Brasilia: Ministério da Saúde; 2010 [citado 2010 Jun 20]; Disponível em: http://conselho.saude.gov.br/Web_comissoes/conep/index.html
6. International Commitee of Medical Journal Editors. Vancouver: ICMJE; 2009 [cited 2010 Jun 20]; Available from: http://www.icmje.org/

7. Brasil. Ministério da Saúde. Sistema Nacional de Informação sobre Ética em Pesquisa envolvendo Seres Humanos. Brasília: SISNEP; 2010 [citado 2010 Jun 20]; Disponível em: http://portal2.saude.gov.br/sisnep/.

8. Novack G. Data Monitoring Committees. Ocul Surf. 2010;8(1):40-3.

9. Animal research is a source of human compassion, not shame. Lancet. 2004; 364(9437):815-6. Comment in: Lancet. 2004;364(9444):1486.

10. Osborne N, Payne D, Newman M. Journal editorial policies, animal welfare, and the 3Rs. Am J Bioeth. 2009;9(12):55-9. Comment in: Am J Bioeth. 2009;9(12):W3. Am J Bioeth. 2009;9(12):61-2. Am J Bioeth. 2009;9(12): 62-4. Am J Bioeth. 2009;9(12):66-7. Am J Bioeth. 2009;9(12):64-6. Am J Bioeth. 2009;9(12):60-1.

11. Brasil. Ministério da Ciência e Tecnologia. Decreto n. 6.899/09. Lei n. 11.794/08. Lei Arouca. Brasilia: Ministério da Ciência e Tecnologia; 2009 [citado 2010 Jun 16]; Disponível em: http://www.mct.gov.br/index.php/content/view/ 308551.html.

12. Rezende A, Peluzio M, Sabarense C. Experimentação animal: ética e legislação brasileira. Rev Nutr [Internet].2008; [citado 2010 Jun 20];21(2):237-42. Disponível em: http://www.scielo.br/pdf/rn/v21n2/v21n2a10.pdf

\section{Envie seu trabalho pelo site dos ABO . \\ www.aboonline.com.br}

